\title{
Sustainability Assessment of Asset Management Decisions for Wastewater Infrastructure Systems-Implementation of a System Dynamics Model
}

\author{
Hamed Mohammadifardi ${ }^{1}$, , Mark A. Knight ${ }^{1,2, *}$ and Andre A. J. Unger ${ }^{3}$ \\ 1 Center for Advancement of Trenchless Technology (CATT), University of Waterloo, 200 University Avenue, \\ Waterloo, ON N2L 3G1, Canada \\ 2 Department of Civil and Environmental Engineering, University of Waterloo, 200 University Avenue, \\ Waterloo, ON N2L 3G1, Canada \\ 3 Department of Earth and Environmental Sciences, University of Waterloo, 200 University Avenue, Waterloo, \\ ON N2L 3G1, Canada \\ * Correspondence: mark.knight@uwaterloo.ca; Tel.: +1-519-581-8835
}

Received: 5 May 2019; Accepted: 5 July 2019; Published: 10 July 2019

check for updates

\begin{abstract}
The goal of this case study is to demonstrate the application and utility of a developed System Dynamics (SD) model to assess the sustainability of strategic decisions for managing the wastewater collection (WWC) pipe network system for a medium-size municipality in Southern Ontario. Two asset management scenarios, suggested by the research-partnered municipality, are adapted based on the acceptable maximum fraction of pipes in the worst condition (ICG5) being equal to (1) $10 \%$ of the network-length/year, and (2) the initial $2.8 \%$ of network-length/year for the entire life cycle of the asset. The urban densification scenarios are restricted to a $50 \%$ urban densification rate. The least maximum rehabilitation rates of $1.41 \%$ and $1.85 \%$ of network length/year are found necessary to keep the ICG5 pipes fractions below the selected $10 \%$ and $2.8 \%$ thresholds, respectively. The maximum and minimum user fee-hike rates for WWC and wastewater treatment (WWT) services are adjusted to support the financial self-sustainability aspect. Results from the SD model, as presented over a 100 year simulation period, show that an accelerated rehabilitation strategy will have a lower financial cost with the lowest greenhouse gas (GHG) emissions. This study highlights the implications of integrating asset management of wastewater-collection and -treatment systems. Applying such an integrated SD model will help decision makers to forecast the future trends related to social, economic, and environmental performances of wastewater infrastructure systems, and evaluate the behavior of interrelated and complex WWC and WWT systems to find synergistic cost-saving opportunities while at the same time improve sustainability.
\end{abstract}

Keywords: rehabilitation; wastewater collection pipe-network; asset management; system dynamics; sustainability assessment

\section{Introduction}

The government of Canada has announced the \$53 billion “New Building Plan" for rejuvenation of Canadian public infrastructure, the largest infrastructure investment in the nation's history [1]. The rehabilitation and expansion of municipal infrastructure, including water and wastewater systems, will not happen without consequences to social, environmental and economic systems. Thus, water and wastewater utilities should consider the long-term sustainability impacts of their decisions when developing their policies and strategic asset management plans. 
The development of socially acceptable, environmentally friendly, and financially viable asset management plans compels understanding of the behavior of social, environmental, and economic systems. The complexity of planning decisions is compounded when different economic, social, and environmental dimensions of the challenge are inherently interrelated [2]. Moreover, it is realized that a strategic asset management plan should include assessment of impacts to/from other affected systems upstream and downstream [3]. Based on recent Asset Management Planning for Municipal Infrastructure regulation [4], municipalities are obligated to coordinate the asset management plans of infrastructures that are connected or interrelated with those of upper-tier municipalities, neighboring municipalities, or jointly owned municipal bodies when preparing strategic asset management policies for their core assets.

This study demonstrates the application and utility of system dynamics (SD) model developed by Mohammadifardi et al. [2] to evaluate the future sustainability performance of policies and asset management strategies for wastewater infrastructure systems. Implementation of the developed SD model for an integrated wastewater collection (WWC) and wastewater treatment (WWT) infrastructure system of a medium-size municipality in Southern Ontario is presented for case-study demonstration. This case study represents a typical city in Canada that own and operate both WWC and WWT infrastructure assets.

The following sections provides the background information and assumptions for the SD model application and presents results for a demonstration case study. The initial data for the physical conditions of the wastewater infrastructure system and the alternative asset management scenarios are presented and discussed in Sections 4 and 5 respectively. The results are presented and discussed in Section 6, and conclusions are drawn in Section 7.

It is important to note that the presented SD model results should be treated as a forecast model that estimates future systems trends and the long-term sustainability performance over a 100-years forecasting period. This model assumes steady state behavior and no shocks occur to the system over this 100 year forecasting period. Thus, the model is to be used as trend forecasting model so the impact of management policies can be seen over the system life-cycle and not an actual prediction of the future model. In the same way, it is inherently and inevitably assumed that the current socio-economic, political, environmental, and technological conditions will be at steady state so that the influence of strategic decisions on life cycle performance of wastewater infrastructure systems can be investigated.

\section{Literature Review}

The application of SD modeling approach for infrastructure asset management strategy development is first introduced by Rehan et al. [5] whom showed the merits of SD modeling approach to depict and model the complex and interconnected physical, social, and financial systems related to water and wastewater infrastructure systems. Rehan and others [6-8] developed a decision making tool for financially sustainable water and wastewater infrastructure asset management. Ganjidoost [9] built on Rehan et al. [6-8] SD models and added the interconnections and feedback between the WWC and water distribution (WD) systems that demonstrated deterioration of water mains can cause them to break, and consequent increasing water leakage can increase infiltration and deterioration of the WWC pipe network system.

Recently, Mohammadifardi et al. [2] advanced the Ganjidoost [9] model by including the: (1) population growth, (2) urban development, (3) WWT plants' physical and financial models and (4) energy footprint and greenhouse gas (GHG) emission modules. They also presented several causal loop diagrams (CLDs) to show the cause and effect chain mechanism between the social, financial, and environmental sectors related to the wastewater-collection and -treatment asset management decisions.

Mohammadifardi et al. [2] discussed that the WWC and WWT systems are directly linked to each other. Wastewater from urban areas is collected in WWC pipe networks and sent to treatment facilities. The increased groundwater infiltration into the WWC pipe network due to increased deterioration of WWC pipes, growing population and extended WWC network system lead to increasing wastewater 
volume and changing the wastewater composition at the WWT plants. They also showed that the increased operational and capital expenses at WWT plants can reinforce the deterioration of WWC systems through the interconnected socio-economic system.

\section{Goal and Scope Definition}

The goal of this case study is to assess the sustainability of strategic decisions for managing the WWC pipe network system for a medium-size municipality in Southern Ontario. The main attribute of the strategic asset management decision is the 'acceptable maximum fraction of WWC pipes in worst internal-condition grade' or ICG5-based on the UK-Water Research Center (WRc) [10] condition-grade rating system. This policy lever was introduced in Rehan et al. [5] to control the level of service or performance of the WWC system.

The subordinated policy levers, such as maximum rehabilitation and user fee-hike rates, should be adjusted to continue provision of WWC, as well as, WWT services within the financial self-sustainability paradigm. The finance strategic decision is simplified to the pay-as-you-go strategy only. Borrowing or capital reserving options are not included in this assessment.

The three indicators listed below are selected respectively from the financial, social, and environmental sectors for sustainability assessment:

1. The average affordability of the WWC and WWT services for a residential user who is expected to use the services for 100 years;

2. Life cycle cost of asset management to continue provisioning of the WWC and WWT services for the municipality;

3. Life cycle GHG emissions from WWC pipe network system and other infrastructure affected by the strategic decisions.

These sustainability assessment indicators are calculated for 100 years connection to the WWC and WWT services and represent the functional unit (FU) of the sustainability assessment. The 100-year timeframe is selected to capture the lifecycle of the pipes and represents the greatest possible longevity within the infrastructure system [7]. The system boundary for the environmental sustainability assessment is extended beyond the WWC pipe network system to assess the changes in GHG emissions from water treatment (WTP) and WD systems, WWT plants, and consequential GHG emission from road traffic disturbances due to WWC pipe construction activities.

\section{SD Model Implementation}

The CLDs, which presents the cause-and-effect interactions between the various components in the physical, social, finance, and natural-environment sectors, as well as, the quantitative modeling and parameterization of the CLDs, are discussed in Mohammadifardi et al. [2]. In the following section, initial data entries and assumptions needed for simulation of the asset management strategies are described.

\subsection{Data Inventory}

\subsubsection{Physical Sector}

The physical sector consists of a combined WWC pipe deterioration model and a WWT plant capacity-expansion model. The WWC pipe inventory is classified into five internal-condition grades (ICG) using the UK Water Research Center rating system [10], and into five different pipe materials. ICG1 represent the pipes in the best condition, and ICG5 represents the pipes in the worst condition. The remaining service life of each pipe and its maintenance cost are determined based on its condition grade and material, as described in Rehan et al. [5,7]. The distribution of pipes in each condition grade is presented in Table 1 . 
Table 1. Wastewater collection (WWC) pipe inventory.

\begin{tabular}{cccccc}
\hline Pipe Material & Pipes in Each Internal-Condition Grade (ICG) (km) \\
& $\mathbf{1}$ & $\mathbf{2}$ & $\mathbf{3}$ & $\mathbf{4}$ & $\mathbf{5}$ \\
\hline Asbestos Cement (AC) & 0.8 & 342.7 & 77.9 & 8.0 & 0.3 \\
Brick + Vitrified Clay (VC) & 0.6 & 4.4 & 41.1 & 159.6 & 37.6 \\
Cast Iron (CI) + Ductile Iron (DI) + Steel (St) & 0.3 & 11.9 & 5.0 & 3.7 & 0.2 \\
$\quad$ Concrete & 97.4 & 701.3 & 881.1 & 190.9 & 45.7 \\
Polyvinyl Chloride (PVC) and High Density & 180.4 & 2.1 & 1.0 & 1.1 & 0.2 \\
Polyethylene (HDPE) & & & & & \\
\hline
\end{tabular}

The total $2795 \mathrm{~km}$ WWC pipe network, comprised of $1916 \mathrm{~km}$ of concrete pipes that are mostly in the ICG2 and ICG3 categories; $430 \mathrm{~km}$ of Asbestos Cement (AC) pipes and $243 \mathrm{~km}$ of pipes made of bricks and Vitrified Clay (VC) that are mainly in the ICG4 category; $185 \mathrm{~km}$ of Polyvinyl Chloride (PVC) and High Density Polyethylene (HDPE) in the best condition grade (ICG1); and a remaining $21 \mathrm{~km}$ of metallic pipes such as Cast Iron (CI), Ductile Iron (DI) and Steel (St) pipes mainly in ICG2 to 4 .

Six WWT plants are connected to the WWC pipe network system as shown in Table 2. The main WWT plant has 153 million liters per day treatment capacity and is equipped with an incineration plant. The bio-solid sludge from other WWT plants is transported by trucks to this treatment facility.

Table 2. Wastewater treatment (WWT) plant data inventory.

\begin{tabular}{cccc}
\hline WWT Plant & $\begin{array}{c}\text { Treatment Capacity } \\
\text { (million L/day) }\end{array}$ & $\begin{array}{c}\text { Current Reserve } \\
\text { Capacity }\end{array}$ & $\begin{array}{c}\text { Average Inflow Suspended Solid } \\
\text { Concentration (mg/L) }\end{array}$ \\
\hline 1 & 29.600 & $21 \%$ & 259 \\
2 & 152.750 & $24 \%$ & 264 \\
3 & 13.620 & $34 \%$ & 259 \\
4 & 28.270 & $17 \%$ & 644 \\
5 & 0.560 & $30 \%$ & 207 \\
6 & 20.700 & $25 \%$ & 317 \\
\hline
\end{tabular}

The initial total capacity of WWT plants is around 90 million $\mathrm{m}^{3} /$ year. On average, $23 \%$ of the WWT plants' capacity is reserved for handling surge flows during flood events. The initial average suspended solid concentration of wastewater-inflow is recorded as 325 milligram per liter $(\mathrm{mg} / \mathrm{L}$ ).

\subsubsection{Finance Sector}

To achieve financial sustainability, revenue must equal expenses. Income is generated from collecting user WWC and WWT fees, development charges, interest earnings, and service connection fees. Table 3 shows the initial unit development charges for different types of development used by the City of London, Ontario [11].

Table 3. Initial unit development charges.

\begin{tabular}{ccc}
\hline Development Type & Charges * & Unit \\
\hline Apartment \& Lodging & 3706 & $\$ /$ unit \\
Townhouse \& Semi/Single & 5932 & $\$ /$ unit \\
Non-residential & 38 & $\$ / \mathrm{ft}^{2}$ \\
\hline
\end{tabular}

* It is assumed that one fourth of the development charges are allocated for building new treatment plant capacity, and the rest are paid for upgrading or constructing other infrastructure.

The initial user fees for WWC and WWT are $\$ 0.59 / \mathrm{m}^{3}$ and $\$ 0.50 / \mathrm{m}^{3}$ respectively to set revenue equal to expenses at the start of the model simulation. Development charges are due when permits for construction of new residential buildings or non-residential areas are issued. 
The connection-service charges are based on water-meter sizes and are collected on a monthly basis. Table 4 shows the initial number of meters of different sizes and corresponding monthly service charges.

Table 4. Service connection charges and number of water-meters.

\begin{tabular}{ccccccccccc}
\hline $\begin{array}{c}\text { Diameter of } \\
\text { Water-Meter }(\mathbf{m m})\end{array}$ & $\mathbf{1 5}$ & $\mathbf{1 9}$ & $\mathbf{2 5}$ & $\mathbf{4 0}$ & $\mathbf{5 0}$ & $\mathbf{7 5}$ & $\mathbf{1 0 0}$ & $\mathbf{1 5 0}$ & $\mathbf{2 0 0}$ & $\mathbf{2 5 0}$ \\
\hline $\begin{array}{c}\text { Number of meters } \\
\begin{array}{c}\text { Connection charges } \\
(\$ \text { month })\end{array}\end{array}$ & 106,806 & 1975 & 2441 & 877 & 1338 & 50 & 36 & 33 & 8 & 0 \\
\hline
\end{tabular}

Expenses are classified under operational and capital expenditures. Capital activities include the rehabilitation of WWC pipes and construction of new WWT plant capacity. The unit costs of ICG5 and ICG4 pipes rehabilitation are considered to be $\$ 1000 / \mathrm{m}$ and $\$ 700 / \mathrm{m}$, respectively [12]. The capital cost for WWT plant capacity expansion is considered to be $\$ 3000 / \mathrm{m}^{3}$ [13].

\subsubsection{Consumer Sector}

The initial population of the studied city is 377,000 people, but this number is assumed to increase by $0.1 \%$ each year. The price elasticity of water demand, which represents the percentage change in water demand per corresponding percentage change in water service fee, is assumed to be a constant -0.35 . The initial water demand of residential users is 186 liters per capita per day (LPCD), with the minimum water demand set at 150 LPCD, and the initial annual water demand of non-residential users is 19.75 million cubic meters.

\subsubsection{Environment Sector}

Table 5 shows the energy-use rate and GHG emission factors for the processes that are considered in the GHG emission calculation.

Table 5. Energy-use data and greenhouse gas (GHG) emission factors.

\begin{tabular}{|c|c|c|c|}
\hline $\begin{array}{c}\text { Energy-Use of Processes That Are Accounted for in } \\
\text { the Energy Footprint Assessment }\end{array}$ & Value & Unit & References \\
\hline Life cycle energy-use of PVC pipes manufacturing & 75.2 & mega joules $/ \mathrm{kg}$ & [14] \\
\hline Life cycle energy-use of water treatment system & 2.4 & mega joules $/ \mathrm{m}^{3}$ & [15] \\
\hline Energy-use of water distribution system & 1.224 & mega joules $/ \mathrm{m}^{3}$ & [16] \\
\hline Energy-use of WWC system & 0.23 & mega joules $/ \mathrm{m}^{3}$ & [16] \\
\hline $\begin{array}{l}\text { Life cycle energy-use of WWT system (including } \\
\text { sludge transportation, incineration, and disposal) }\end{array}$ & 1.55 & mega joules $/ \mathrm{m}^{3}$ & [16] \\
\hline Life cycle energy-use in pipe installation & 405 & $\mathrm{kwh} / \mathrm{m}$ & [17] \\
\hline $\begin{array}{c}\text { GHG emission factors for rehabilitation of ICG4 pipes } \\
\text { using trenchless technologies }\end{array}$ & 2 * & $\mathrm{kg} \mathrm{CO} 2$ eq. ${ }^{* * / m}$ & [18] \\
\hline $\begin{array}{l}\text { GHG emission factors for replacement of ICG5 and } \\
\text { new pipes installation using open-cut technologies }\end{array}$ & $64 *$ & $\mathrm{~kg} \mathrm{CO} 2$ eq. $/ \mathrm{m}$ & [18] \\
\hline $\begin{array}{l}\text { GHG emission factor for one kwh electrical energy } \\
\text { production and transmission in Ontario }\end{array}$ & 125 & $\mathrm{~g} \mathrm{CO}_{2 \text { eq. }} / \mathrm{kwh}$ & [19] \\
\hline
\end{tabular}

* Daily traffic is assumed to be 3500 vehicles/day. ${ }^{* *} \mathrm{CO}_{2}$ equivalent (eq.) unit is used for climate-change impact characterization in LCA [20].

The direct GHG emission is calculated based on the $\mathrm{N}_{2} \mathrm{O}$, and $\mathrm{CH}_{4}$ gas emissions from wastewater collection and treatment systems [21]. $\mathrm{CO}_{2}$ emission is not accounted for since it is classified as "biogenic" emission, i.e., it would otherwise have been emitted through natural processes of decay [21]. The methane gas emission is considered to be zero as the demotic and industrial wastewater is treated in the centralized treatment systems where secondary-mechanical treatments are applied to remove 
most organic matter. The nitrous oxide emissions from treatment processes are considered to be four $\mathrm{g} /$ person/year by attributing the industrial and commercial discharges to residential users [21]. The indirect GHG emissions are from the production and supply of material and energy resources or from the affected adjacent infrastructure systems.

\section{Asset Management Scenarios}

The alternative asset management scenarios and subordinated policy levers are presented in Table 6.

Table 6. Estimated policy levers in alternative scenarios.

\begin{tabular}{ccc}
\hline Policy Levers & $\begin{array}{c}\text { Scenario 1: Base-Line } \\
\text { Rehabilitation }\end{array}$ & $\begin{array}{c}\text { Scenario 2: Accelerated } \\
\text { Rehabilitation }\end{array}$ \\
\hline 1- Max. replacement and rehabilitation rate (\% of the network & 1.41 & 1.85 \\
length/year) & 8.45 & 12.5 \\
2- Max. allowable WWC fee-hike rate (\% per annum) & 11.5 & 3.5 \\
3- Max. allowable WWT fee-hike rate (\% per annum) & 0 & 0 \\
4- Min allowable WWT fee-hike rate (\% per annum) & 12.6 & 5 \\
5- Max allowable development charge hike rate (\% per annum) & 0 & 0 \\
6- Min allowable development charge hike rate (\% per annum) & & \\
\hline
\end{tabular}

The base-line asset management scenario is defined based on the acceptable maximum fraction of ICG5 pipes being equal to $10 \%$ of the network-length/year and is commonly employed as a reasonable asset management policy in literature, e.g., $[5,6,8,22]$. An alternative scenario is to keep the ICG5 pipes fraction below the initial $2.8 \%$ of network-length/year for the entire life cycle of the asset. This strategy is suggested to maintain the current service level of WWC systems for users and accelerate the rehabilitation and replacement of deteriorated WWC pipes. The urban densification scenarios is restricted to a $50 \%$ urban densification rate.

The subordinated policy levers, such as the maximum rehabilitation rate, and maximum or minimum user fee-hike rates for WWC and WWT services are adjusted to support the selected strategic decisions. The maximum rehabilitation rates of $1.41 \%$ and $1.85 \%$ of network length/year are identified, by trial and error, to keep the ICG5 pipes fractions below the selected $10 \%$ and $2.8 \%$ thresholds, respectively. The lowest maximum WWC fee, WWT fee, and development charge hike rates are found to be respectively $8.45 \%, 11.5 \%$, and $12.6 \%$ per annum for the base-line scenario, and $12.5 \%, 3.5 \%$, and $5 \%$ per annum for the accelerated rehabilitation scenario.

\section{Presentation of Results}

The future behavior of the wastewater collection system and social, finance, and environmental performances of asset management scenarios are projected in this section. Figures 1-11 provide a means of understanding the future trends and forecasting the sustainability outlook of the strategic decisions in the asset management planning process. Figure $1 \mathrm{a}, \mathrm{b}$ respectively represent the fraction of the ICG5 and ICG4 pipes respectively over the 100-year simulation period in each scenario.

Figure 1a shows that the adjusted maximum rehabilitation rates of $1.41 \%$ and $1.85 \%$ (network length/year) suffice to maintain the ICG5 pipes fractions below 10\% and 2.8\% (network length/year) respectively in the base-line and accelerated-rehabilitation scenarios. 


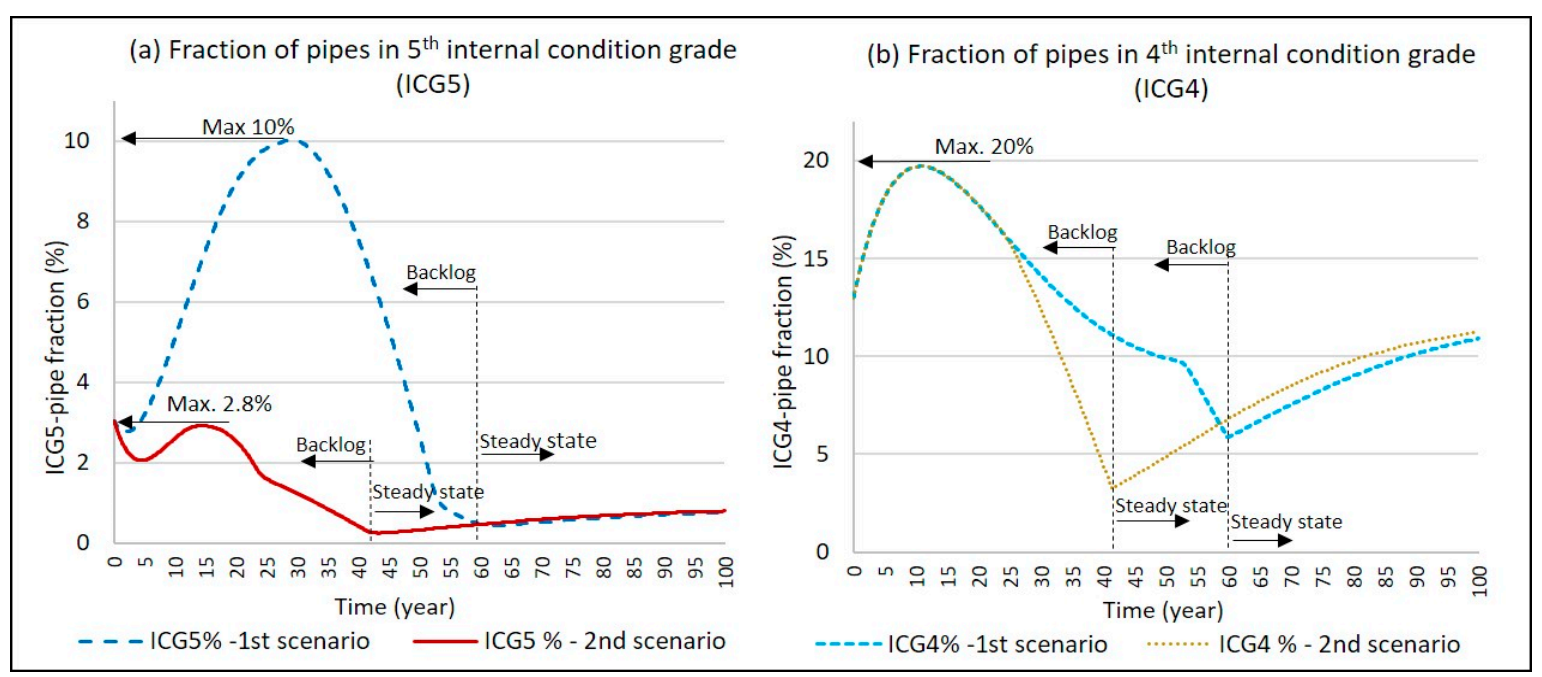

Figure 1. (a) Fraction of ICG5 pipes; (b) fraction of ICG4 pipes.

The fraction of ICG5 pipes in the base-line scenario (1.41\% rehabilitation rate) increases to the maximum $10 \%$ threshold within 30 years; then, it reduces to lower than the initial $2.8 \%$ level after about 50 years. Therefore, users can experience a better than initial-level service only after 50 years subscription to the WWC and WWT services with every-year increased fees. After year 60, the WWC physical sector reaches a steady state where all ICG5 and ICG4 pipes are replaced annually until the end of the simulation period of 100 years.

The ICG5 pipes fraction in the accelerated-rehabilitation scenario (1.85\% rehabilitation rate) will reduce to $2 \%$ during the first 5 years as the deterioration rate of the ICG4 pipes turning into the ICG5 pipes is lower than the replacement rate of the ICG5 pipes with new pipes i.e., ICG1 pipes. After 5 years, this trend is reversed and the ICG5 pipes fraction increase to reach the initial $2.8 \%$ level in year 15 . In year 25, the fraction of ICG5 pipes are reduced to less than $1.85 \%$ of the network length. Therefore, the model starts to renovate ICG4 pipes to fill-up the annual rehabilitation capacity. The fraction of ICG4 and ICG5 pipes reach their lowest level at year 40 . After 40 years, the infrastructure backlog is eliminated and steady state is achieved i.e., all ICG5 and ICG4 pipes are replaced annually until the end of the simulation period of 100 years.

Figure $2 \mathrm{a}, \mathrm{b}$ presents the actual rehabilitation rates and related capital expenses respectively for each scenario.

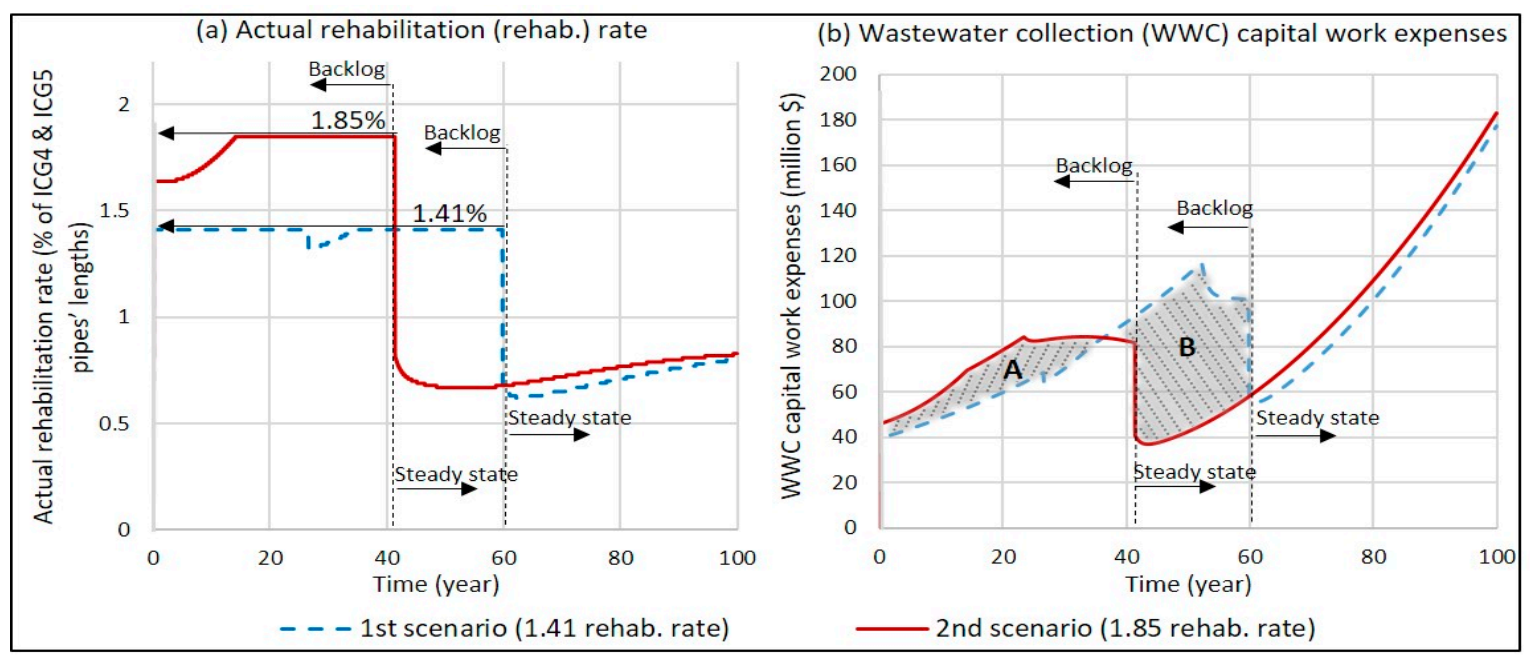

Figure 2. (a) Actual WWC pipes rehabilitation rate; (b) capital work expenses for WWC system. 
As shown in Figure 2a, the highest rehabilitation rate of $1.85 \%$ in the second scenario is achieved after about 15 years and concludes in about year 40, at the onset of the steady-state. In the first scenario, the base-line rehabilitation rate of $1.41 \%$ starts from the initial year and continues for about 60 years until it joins the same steady-state of the second scenario.

It should be noted that the actual rehabilitation rate depends on the availability of pipes in ICG5 or ICG4 categories and the existence of a positive funds balance. In Figure 2a, the actual rehabilitation rate in the second scenario is lower than the maximum rehabilitation rate of $1.85 \%$ during the first 15 years due to a lack of funds, then it drops to nearly $0.5 \%$ after 40 years when the backlog inventory of ICG5 and ICG4 pipes are eliminated.

Figure $2 b$ shows the WWC pipes rehabilitation and replacement costs. As expected, the accelerated rehabilitation rate in the second scenario incurs higher capital expenses until about year 35. However, the annual capital expenses for the base-line scenario surpass the annual capital expenses of the second scenario for the next 25 years. The hatched ' $\mathrm{A}$ ' area represents the additional capital investments used to accelerate the WWC pipes rehabilitation and replacement in the second scenario. It is evident that this additional capital investment is smaller than the required capital expenses in the base-line scenario which is the hatched ' $\mathrm{B}$ ' area.

The annual total wastewater-inflow volume and the built treatment plants capacities in each scenario are presented in Figure 3a,b respectively. The annual wastewater volume in the base-line scenario increases for about 30 years until it reaches its maximum level of 104 million $\mathrm{m}^{3} / \mathrm{day}$. In the second scenario, the annual wastewater volume will not exceed the initial level until year 80 . In Figure 3a, the additional wastewater volume that requires building WWT plant capacity in the first scenario is hatched (area denoted as ' $\mathrm{A}$ ').



Figure 3. (a) Total wastewater-inflow volume to WWT plants; (b) built WWT capacity.

The built WWT capacity presented in Figure 3b corresponds with the WWT plant's annual wastewater-inflow volume. In the first scenario, the increased wastewater-inflow volume imposes the need to build additional treatment capacities from the initial years until year 30 (when the wastewater volume is at its maximum level), whereas in the second scenario, this need does not arise until about year 80 .

The WWT plant's capacity is required to treat the sewage generated by residential and non-residential users, as well as, the extraneous inflow and infiltration (I\&I) to the WWC pipe network system. Figure 4 demonstrate the proportion of each element in the WWT plant's wastewater-inflow volume. 


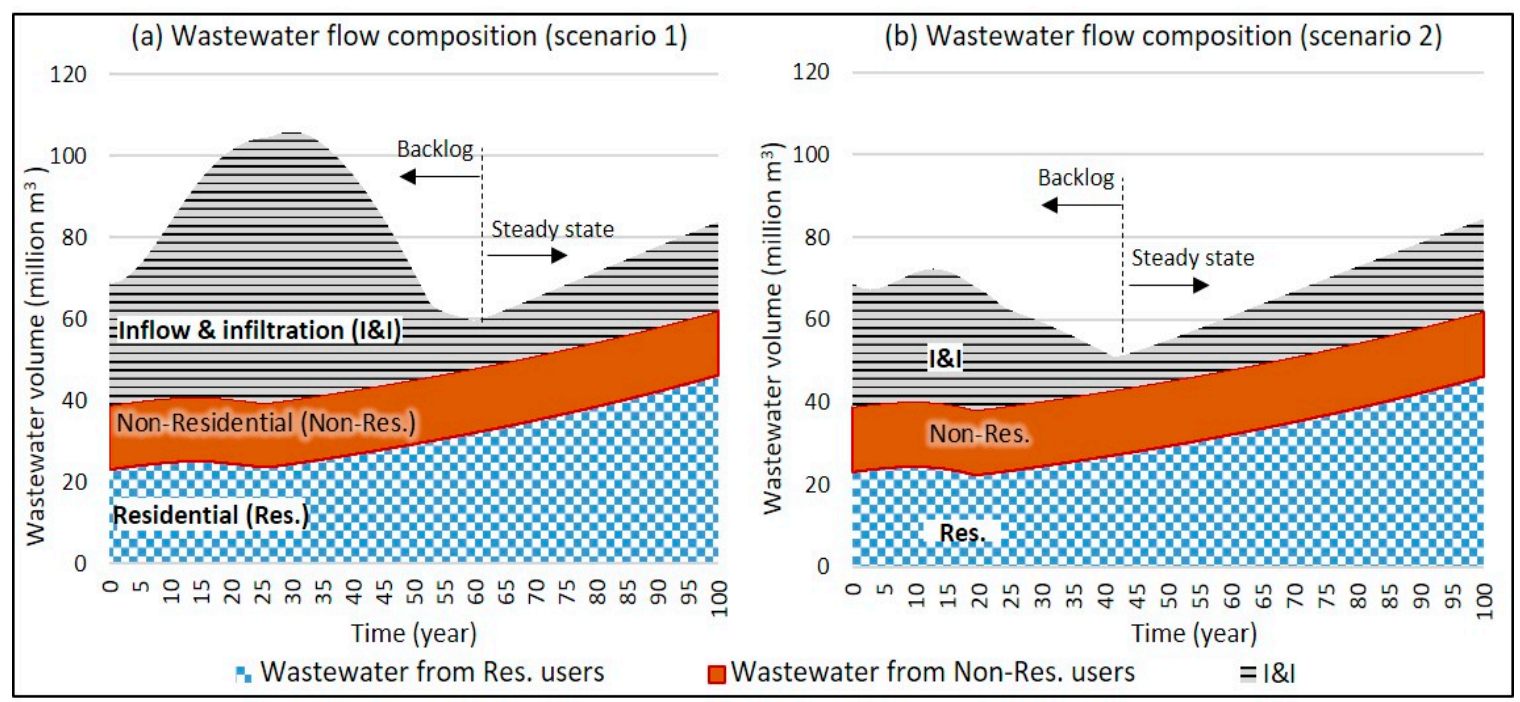

Figure 4. Proportion of I\&I and generated sewage volumes in (a) the 1-st scenario with the maximum $1.41 \%$ rehabilitation rate and $(\mathbf{b})$ the 2 -nd scenario with the maximum $1.85 \%$ rehabilitation rate.

Comparing the disaggregated wastewater volumes in Figure 4 confirm that the main difference between the WWT plant's wastewater-inflow volume originates from the differences in I\&I volume. The total extraneous I\&I flow volume in the base-line scenario, presented in Figure 4a, is about 1.5 billion $\mathrm{m}^{3}$ higher than the I\&I flow in the second scenario. The underlying cause of this difference is the higher fraction of deteriorated ICG5 and ICG4 pipes in the first scenario than the second scenario as presented in Figure 1.

The volumes of wastewater generated by residential and non-residential users are relatively identical in both scenarios, and water conservation has a negligible impact on total wastewater flow volumes. In the first scenario, only the extraneous I\&I flow volume will impose building extra wastewater treatment capacity in the first 35 years (Figure 3a); whereas, in the second scenario, the population growth will result in increased sewage volume by residential that will result in building increased WWT plant capacity after 80 years.

Figure 5 shows the total user fee in Figure $5 \mathrm{a}$ and the water demands in Figure $5 \mathrm{~b}$ for residential users. The user fees are presented based on the present dollar value. The user fee in the first scenario increases to reach its peak value of $3.5 \$ / \mathrm{m}^{3}$ in year 50, whereas in the second scenario, the user fee reaches its highest value, $3.1 \$ / \mathrm{m}^{3}$, in about year 22 .

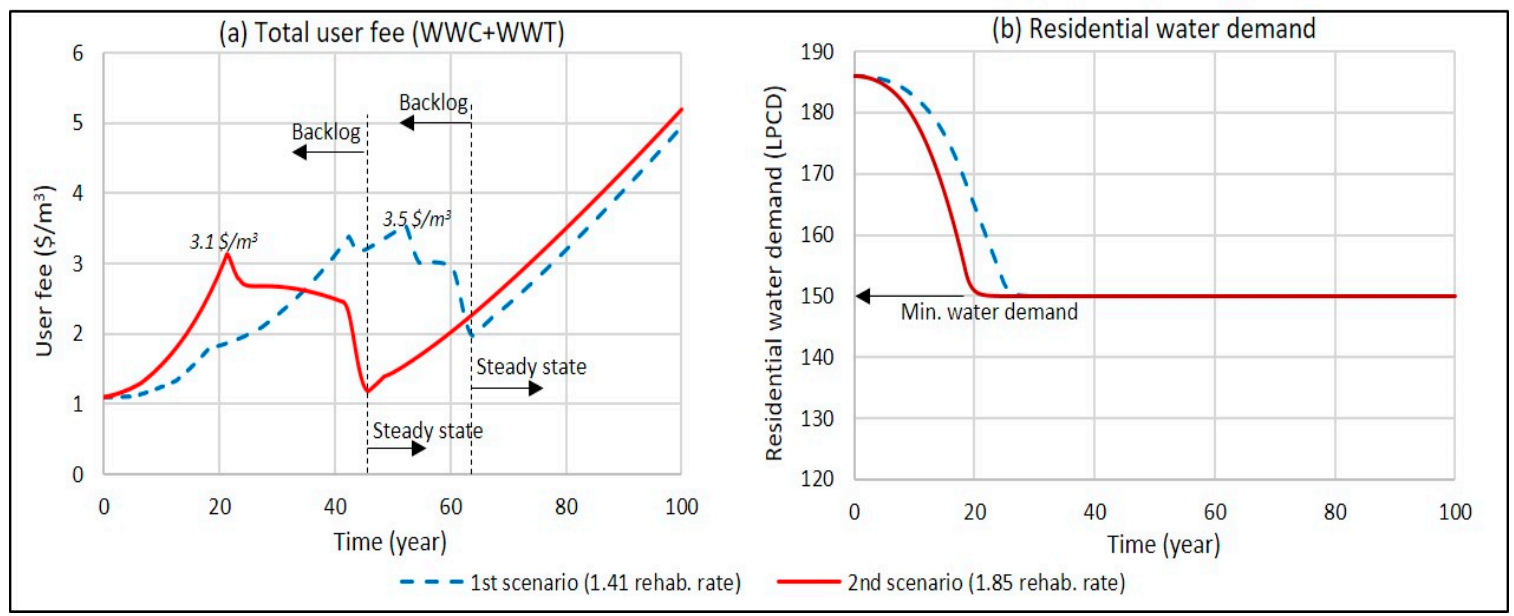

Figure 5. (a) Residential total user fees; (b) residential water demand. 
Since the user fees increase in both scenarios, residential users reduce their water demand to minimum level of 150 LPCD, as presented in Figure $5 \mathrm{~b}$. The minimum water demand level will be reached about 5 years earlier in the second scenario than in the first. The lower water demand level is maintained as residents adopt their water use behavior for the rest of the asset-management life cycle.

Figure 6 presents the disaggregate WWT and WWC fees for residential users in each scenario. Comparing the WWC and WWT fees highlights the significance of WWC fees in user fee variations. In the first scenario, Figure 6a, the contribution of WWT fees is significant for the first 20 years and then starts to diminish over time. In the second scenario, Figure $6 \mathrm{~b}$, the WWT fee contribution decreases from the beginning, up to the end of the simulation when the user fees reach about their maximum, $5 \$ / \mathrm{m}^{2}$, in both scenarios.

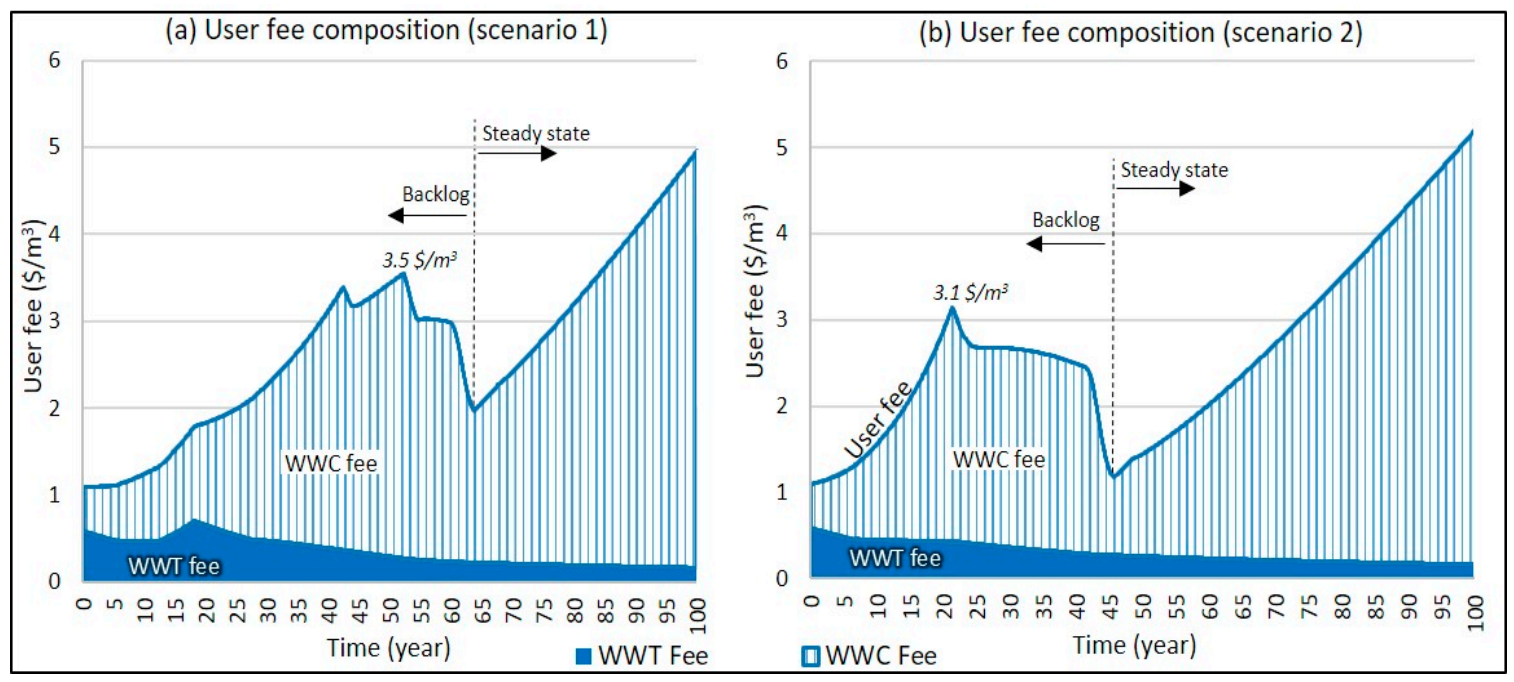

Figure 6. Proportion of WWT and WWC fees in annual user fee results for (a) the 1-st scenario with $1.41 \%$ rehabilitation rate and $(\mathbf{b})$ the 2 -nd second scenario with $1.85 \%$ rehabilitation rate.

Figure 7 shows the changes in development charges based on the present dollar value. In the first scenario, the development charges will start to increase from year 10 and reach their highest value of approximately $\$ 5000$ for new apartments, $\$ 10,000$ for new houses, and $\$ 60 / \mathrm{m}^{2}$ for new non-residential buildings in year 22. After the year 22, the utility can generate enough revenues to pay for both operational and capital expenses, and the development charges continuously depreciate to reach to the lowest values of $\$ 439$ for new houses, $\$ 274$ for new apartments, and $\$ 2.81 / \mathrm{m}^{2}$ for non-residential developments at the end of the simulation period. In contrast, the development charges in the second scenario continuously depreciate from the beginning and reach less than $\$ 1000$ for new residential units and $\$ 5 / \mathrm{m}^{2}$ for non-residential developments in year 50 . 


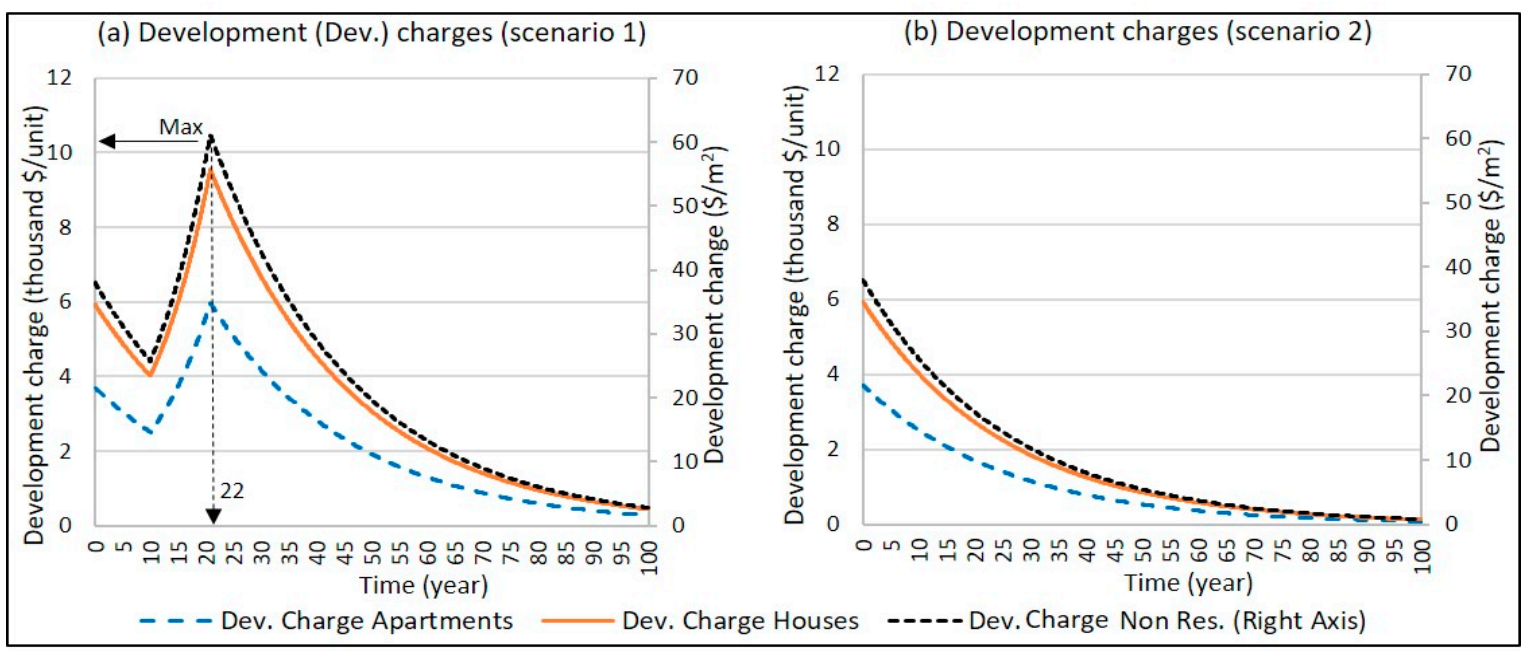

Figure 7. Development charges in (a) the 1-st scenario with maximum $1.41 \%$ rehabilitation rate, and (b) the 2 -nd scenario with maximum $1.85 \%$ rehabilitation rate.

The annual energy-use and GHG emission results are presented in Figure 8a,b, respectively. The annual energy-use in the first scenario is slightly lower than that in the second scenario until about year 10, and it reaches 500 gigajoules/yr in about year 35. The energy-use in the second scenario reaches about 450 gigajoules/yr in about year 15 and starts to decline to as low as 350 gigajoules/yr in the second scenario in about year 40. A similar comparison is attainable for the annual GHG emission results. The annual total GHG emission in the first scenario rises to above 8.5 million tones $\mathrm{CO}_{2}$ eq. in about year 35, whereas it drops to below 5.5 million tones $\mathrm{CO}_{2}$ eq. in the second scenario in about year 40. Hatched area ' $\mathrm{A}$ ' and ' $\mathrm{B}$ ' represent the additional total energy-use and GHG emissions result from implementing the 1.41 baseline rehabilitation rate scenario.

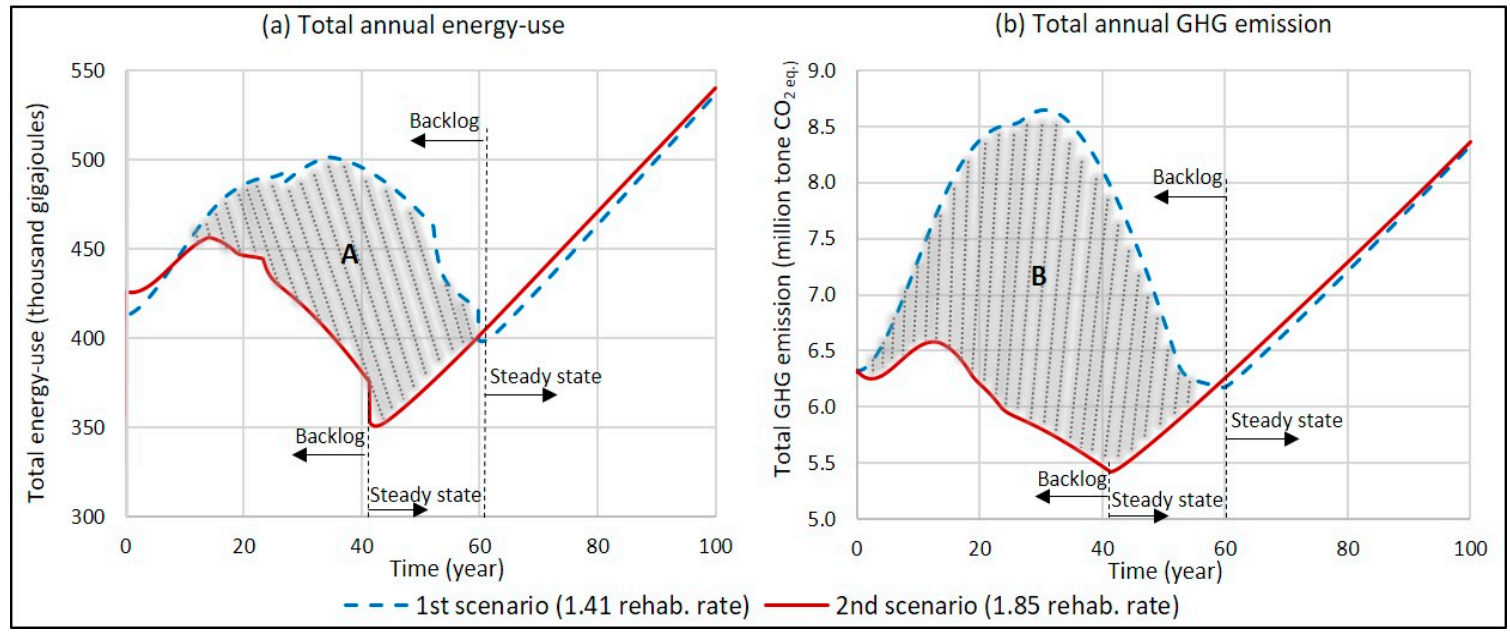

Figure 8. (a) Total energy-use; (b) total GHG emission results.

The contributions of different processes associated with the total GHG emissions in the first and second scenarios are presented in Figure 9a,b, respectively. The main variations in GHG emissions in both scenarios result from the variation of GHG emissions from WWT plant processes, and correlate to the variations in I\&I volume presented in Figure 4. 




Figure 9. Proportion of GHG emission from different sources in total annual GHG emissions based on data presented in Table 5 for (a) the 1-st scenario with the maximum $1.41 \%$ rehabilitation rate, and (b) the 2-nd scenario with the maximum $1.85 \%$ rehabilitation rate.

Aggregated GHG emission results, presented in Figure 10, illustrate that the largest GHG emissions are attributed to the water distribution and WWT plant processes; whereas, the GHG emissions from capital work and WTP processes have negligible contribution to the total GHG emissions.

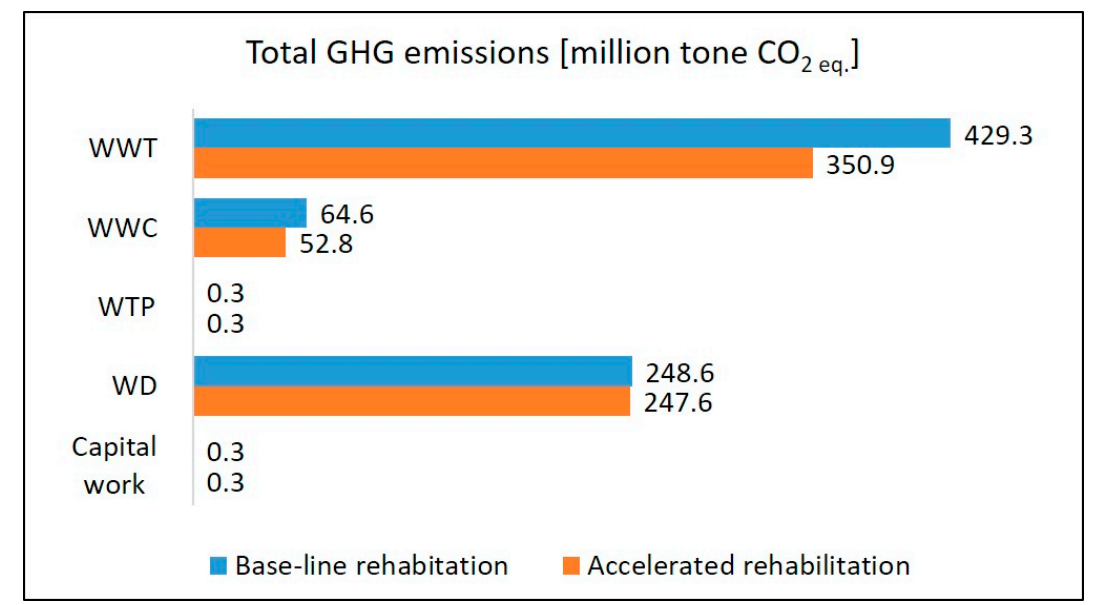

Figure 10. Total GHG emissions from different processes.

Figure 11 is presented to compare the total annual operational and capital expenses of WWC pipe network and treatment plant systems, based on the present dollar value, when base-line and accelerated rehabilitation strategies are implemented. The capital expenses of WWC systems are the main variable in the asset management costs in both scenarios. For the first 40 and 57 years of the asset life cycle, respectively in the first and second scenarios, capital expenses are the highest cost to the WWC and WWT systems and represent the infrastructure backlog needed to bring the assets to a state of good repair. Later, the operational expenses of WWC systems become more significant than the capital expenses toward the end of the asset's service life. 




Figure 11. Proportion of operational and capital expenses in total annual expense for (a) 1-st scenario with the maximum $1.41 \%$ rehabilitation rate and (b) 2-nd scenario with the maximum $1.85 \%$ rehabilitation rate.

As presented in Figure 12, the differences between the life cycle costs of the two scenarios are mainly due to the differences in WWC and WWT capital expenses, which are denoted as WWC_CapEx and WWT_CapEx in Figure 12, respectively.

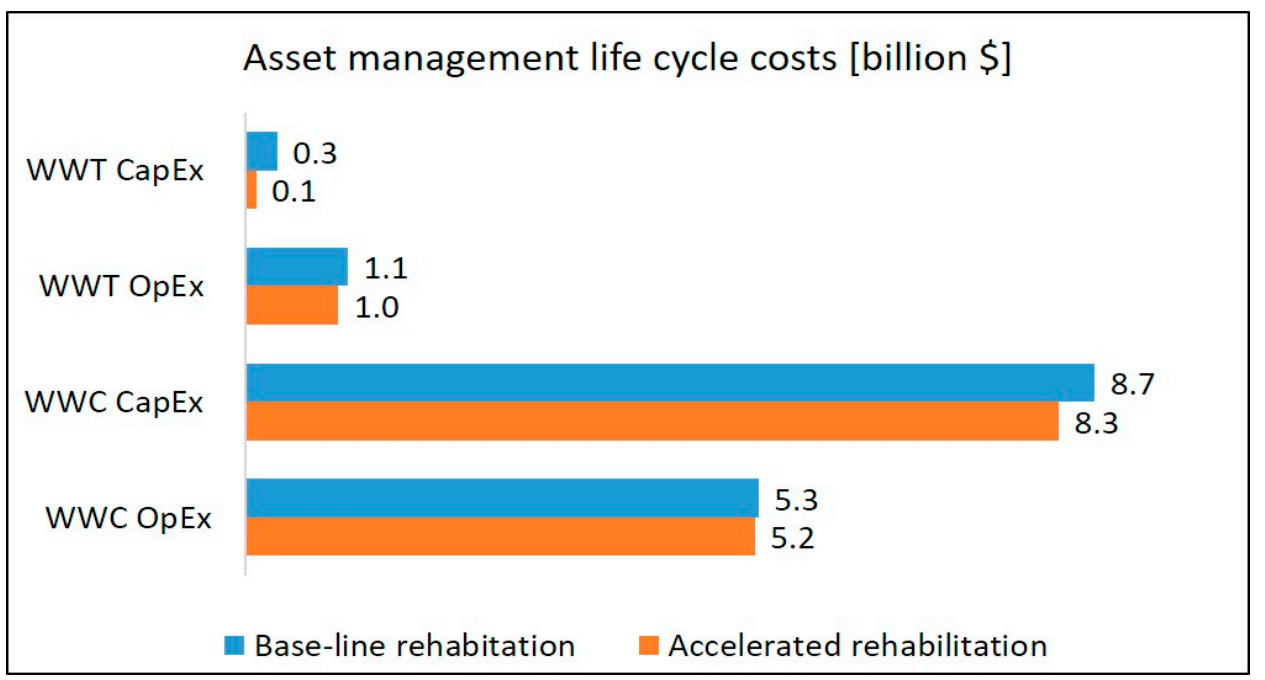

Figure 12. Asset management life cycle cost components.

\section{Summary of Results and Discussion}

The total cost of the WWC and WWT services for a residential user, total cost of asset management activities for the municipality, and the total GHG emissions from the WWC and other affected infrastructure systems are calculated using Equations (1)-(3), respectively. These three indicators are employed to evaluate the social, financial, and environmental sustainability impacts from implementing the proposed strategic decisions on a WWC pipe network system.

$$
\text { User cost }=\sum(\text { WWC fee }(t)+\text { WWT fee }(t)) \times \text { metered water }(t)
$$

where 
- $\mathrm{t}$ [year] represent the current time;

- User cost [\$/year] is the cost of WWC and WWT service for a residential user in 100 years simulation period to captures the life cycle of the assets;

- $\quad W W C$ fee $(t)\left[\$ / \mathrm{m}^{3}\right]$ is the WWC fee paid by a residential user in year $\mathrm{t}$;

- WWT fee ( $\mathrm{t})\left[\$ / \mathrm{m}^{3}\right]$ is the WWT fee paid by a residential user in year $\mathrm{t}$;

- Metered water $(t)\left[\mathrm{m}^{3} /\right.$ year] is the volume of water used by a residential user in year $t$.

$$
\begin{gathered}
\text { Cost to the city }=\left[\left(W W C \_O p E x(t)+W W C \_C a p E x(t)\right)+\left(W W T \_O p E x(t)+\right.\right. \\
\text { WWT_CapEx(t) })]
\end{gathered}
$$

where

- $\quad \mathrm{t}$ [year] represent the current time;

- $\quad$ cost [\$/year] is the cost of asset management operational and capital activities for the integrated WWC and WWT systems in 100 years simulation period to captures the life cycle of the assets;

- WWC_OpEx [\$/year] represents the annual operational expenses for WWC systems in year $\mathrm{t}$;

- WWC_CapEx [\$/year] represents the annual capital-work expenses for rehabilitation and replacement of WWC pipes in year $t$;

- WWT_OpEx [\$/year] represents the annual operational expenses for WWT systems in year t;

- WWC_CapEx [\$/year] represents the annual capital-work expenses for construction of new WWT plant capacities in year $t$.

$$
\begin{gathered}
\text { LC_GHG emisison }=\sum \text { [WTP_GHG(t) + WD_GHG }(\mathrm{t})+\text { WWC_GHG }(\mathrm{t})+ \\
\text { WWT plant_GHG }(\mathrm{t})+\text { CapWork_GHG }(\mathrm{t})]
\end{gathered}
$$

where

- $\quad \mathrm{t}$ [year] represent the current time;

- LC_GHG emission $\left[\mathrm{CO}_{2 \text { eq. }}\right.$. represents the total GHG emissions from implementing asset management strategies in each scenario for the 100 years simulation period;

- WT_GHG $\left[\mathrm{CO}_{2 \text { eq. }}\right.$ ] is the annual GHG emissions from the water treatment plant system in year $[\mathrm{t}]$

- WD_GHG $\left[\mathrm{CO}_{2}\right.$ eq.] is the annual GHG emissions from the water distribution in year $[\mathrm{t}]$;

- WWC_GHG $\left[\mathrm{CO}_{2}\right.$ eq.] is the annual GHG emissions from WWC system in year [t];

- WWT_GHG $\left[\mathrm{CO}_{2}\right.$ eq. $]$ is the annual GHG emissions from WWT plant system in year $[\mathrm{t}]$;

- CapWork_GHG $\left[\mathrm{CO}_{2}\right.$ eq. $]$ is the GHG emissions from rehabilitation and replacement of WWC pipes in year [t].

The calculated result for each sustainability indicator is presented in Table 7.

Table 7. Total cost for different scenarios and stakeholders.

\begin{tabular}{ccc}
\hline Bottom Lines & $\begin{array}{c}\text { Scenario 1: Base-Line } \\
\text { Rehabilitation }\end{array}$ & $\begin{array}{c}\text { Scenario 2: Accelerated } \\
\text { Rehabilitation }\end{array}$ \\
\hline Total cost to a residential user (thousand \$) & 15.1 & 14.6 \\
Total cost to the municipality (billion \$) & 14.2 & 13.8 \\
Total GHG emission (million tone $\mathrm{CO}_{2 \text { eq. }}$ ) & 743.2 & 651.9 \\
\hline
\end{tabular}

The results show that the cost for resident users and for the municipality will be lowered if the accelerated-rehabilitation strategy is employed by the wastewater utility. This accelerated rehabilitation strategy also improves the environmental footprint of the asset management activities in terms of GHG emissions. 
Figure 13 present the affordability results for residential service users. The affordability or bill burden, which represents the percentage of annual average household income paid for wastewater collection and treatment services, stays below the $2.5 \%$ affordability threshold [23] until year 80 under both scenarios. In the second scenario, this social sustainability indicator stays below $1 \%$ for about 60 years until it increases to nearly $5 \%$ at the end of the simulation period. In contrast, in the first scenario, affordability passes $1 \%$ after 35 years and increases steadily each year until it reaches the same trend as the second scenario in about year 65 . The average affordability ratio for the first and second scenarios are $1.52 \%$ and $1.49 \%$ respectively.

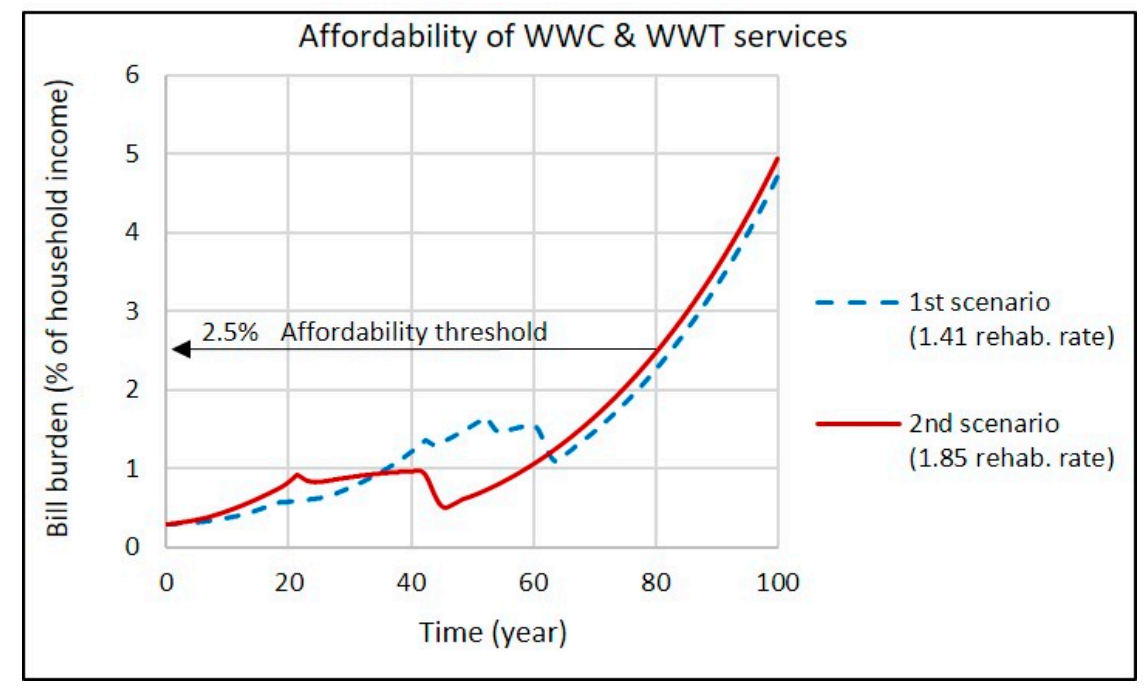

Figure 13. Affordability of wastewater collection and treatment services for residential users.

\section{Conclusions}

Comparing the social, environmental, and economic cost results show that a more cost-effective solution would be reached if a higher rehabilitation rate policy is considered for the presented case-study WWC system. The accelerated rehabilitation strategy will have a lower financial cost, without the need to compromise social or environmental values in achieving a sustainable state.

Based on the EPA guideline [24], the inflow and infiltration are excessive as the cost of I\&I transportation and treatment in the first scenario exceeds the backlogged investment cost of rehabilitation and replacement of the ICG4 and ICG5 pipes. It is shown that the future WWT plant capacity requirement in the base-line scenario mainly results from the I\&I increase which also cause significant GHG emissions. Consideration of GHG emissions from WWT plant system in sustainability assessment leverage the advantages of accelerated rehabilitation strategy over the base-line strategy.

This study highlights the implications of integrating asset management of wastewater collection and treatment systems. Applying such an integrated model will help decision makers to evaluate the behavior of interrelated wastewater-collection and -treatment systems and find synergistic cost-saving opportunities while taking decisions on when, where, and how to invest in infrastructure upgrading and installation.

This study has limitations in evaluating alternative financial management strategies. A more complete assessment would include other financial approaches, such as the borrowing and capital reserving strategies developed and modeled by Rehan et al. [6], to develop other asset management plan alternatives. Moreover, a complete sustainability assessment will embrace evaluation of more environmental and social indicators related to the asset management plans at the strategic level.

Author Contributions: Conceptualization, H.M., M.A.K. and A.A.J.U.; methodology, H.M., M.A.K. and A.A.J.U.; software, M.A.K.; validation, H.M., M.A.K. and A.A.J.U.; formal analysis, H.M.; writing-original draft preparation, H.M.; writing-review and editing, H.M., M.A.K. and A.A.J.U.; supervision, M.A.K. and A.A.J.U.; funding acquisition, M.A.K. and A.A.J.U. 
Funding: This research was funded by Natural Science and Engineering Research Council of Canada (NSERC) and the Centre for Advancement of Trenchless Technology (CATT) located at the University of Waterloo.

Acknowledgments: We gratefully acknowledge the financial support provided by the NSERC and CATT.

Conflicts of Interest: The authors declare no conflict of interest. The funders had no role in the design of the study; in the collection, analyses, or interpretation of data; in the writing of the manuscript, or in the decision to publish the results.

\section{References}

1. Infrastructure Canada 2014-2015 Report on Plans and Priorities Section 1. Available online: http://www. infrastructure.gc.ca/pub/rpp/2014-15/2014-01-eng.html (accessed on 11 October 2018).

2. Mohammadifardi, H.; Knight, M.A.; Unger, A.J.A. Sustainability assessment of asset management decisions for wastewater infrastructure systems-Development of a system dynamic model. Systems 2019, 7, 26. [CrossRef]

3. Mohammadifardi, H. Life Cycle Sustainability Assessment of Asset Management Plans for Municipal Wastewater Systems. Ph.D. Thesis, University of Waterloo, Waterloo, ON, Canada, 2019.

4. Asset Management Planning for Municipal Infrastructure; e-law: Toronto, ON, Canada, 2017.

5. Rehan, R.; Knight, M.A.; Haas, C.T.; Unger, A.J.A. Application of system dynamics for developing financially self-sustaining management policies for water and wastewater systems. Water Res. 2011, 45, 4737-4750. [CrossRef] [PubMed]

6. Rehan, R.; Knight, M.A.; Unger, A.J.A.; Haas, C.T. Development of a system dynamics model for financially sustainable management of municipal watermain networks. Water Res. 2013, 47, 7184-7205. [CrossRef] [PubMed]

7. Rehan, R.; Knight, M.A.; Unger, A.J.A.; Haas, C.T. Financially sustainable management strategies for urban wastewater collection infrastructure-development of a system dynamics model. Tunn. Undergr. Space Technol. 2014, 39, 116-129. [CrossRef]

8. Rehan, R.; Unger, A.J.A.; Knight, M.A.; Haas, C.T. Strategic Water Utility Management and Financial Planning Using a New System Dynamics Tool. J. Am. Water Works Assoc. 2015, 107, 22-36. [CrossRef]

9. Ganjidoost, A. Performance Modeling and Simulation for Water Distribution and Wastewater Collection Networks. Ph.D. Thesis, University of Waterloo, Waterloo, ON, Canada, 2016.

10. WRC. Sewerage Rehabilitation Manual; Water Research Centre: Swindon, UK, 2011.

11. City of London Development Charges. Available online: https://www.london.ca/business/Resources/ Development-Financing/Pages/Development-Charges.aspx (accessed on 5 October 2018).

12. Younis, R. Development of Wastewater Collection Network Asset Database, Deterioration Models and Management Framework. Ph.D. Thesis, University of Waterloo, Waterloo, ON, Canada, 2011.

13. 2015 Wastewater Council Approved Budget; City of London: London, ON, Canada, 2015.

14. Du, F.; Woods, G.; Kang, D. Life Cycle Analysis for Water and Wastewater Pipe Materials. J. Environ. Eng. 2013, 139, 703-711. [CrossRef]

15. Racoviceanu, A.I.; Karney, B.W.; Kennedy, C.A.; Colombo, A.F. Life-Cycle Energy Use and Greenhouse Gas Emissions Inventory for Water Treatment Systems. J. Infrastructure. Syst. 2007, 13, 261-270. [CrossRef]

16. Graham, K. Personal Communication; Water Engineering Division: City of London, ON, Canada, 2012.

17. Prosser, M.; Speight, V.; Filion, Y. Life-Cycle Energy Analysis of Performance- Versus Age-Based Pipe Replacement Schedules. J. Am. Water Works Assoc. 2013, 105, E721-E732. [CrossRef]

18. Rehan, R.; Knight, M.A. Do Trenchless Pipeline Construction Methods Reduce Greenhouse Gas Emissions? Centre for the Advancement of Trenchless Technologies (CATT) Department of Civil and Environmental Engineering University of Waterloo: Waterloo, ON, Canada, 2007; p. 19.

19. Sahely, H.R.; MacLean, H.L.; Monteith, H.D.; Bagley, D.M. Comparison of on-site and upstream greenhouse gas emissions from Canadian municipal wastewater treatment facilities. J. Environ. Eng. Sci. 2006, 5, 405-415. [CrossRef]

20. ISO-14040. ISO-14040 Environmental Management_Life Cycle Assessment_Principles and Framework, 2nd ed.; International Standard Organization (ISO): Winterthur, Switzerland, 2006; Volume 2006. 
21. Doorn, M.R.J.; Towprayoon, S.; Manso Vieira, S.M.; Irving, W.; Palmer, C.; Pipatti, R.; Wang, C. Chapter 6 Wastewater Treatment and Discharge. In Intergovernmental Panel on Climate Change (IPCC) Guidelines for National Greenhouse Gas Inventories; Institute for Global Environmental Strategies (IGES): Hayama, Japan, 2006; Volume 5.

22. Ganjidoost, A.; Knight, M.A.; Unger, A.J.A.; Haas, C.T. Benchmark performance indicators for utility water and wastewater pipelines infrastructure. J. Water Res. Plan. Manag. 2018, 144, 04018003. [CrossRef]

23. Environmental Economics Advisory Committee of the EPA Science Advisory. Affordability Criteria for Small Drinking Water Systems: An EPA Science Advisory Board Report, U.S.; Environmental Protection Agency: Washington, DC, USA, 2002.

24. US Environmental Protection Agency (EPA). Guide for Estimating Infiltration and Inflow, June 2014; EPA: Boston, MA, USA, 2014; pp. 1-7.

(C) 2019 by the authors. Licensee MDPI, Basel, Switzerland. This article is an open access article distributed under the terms and conditions of the Creative Commons Attribution (CC BY) license (http://creativecommons.org/licenses/by/4.0/). 